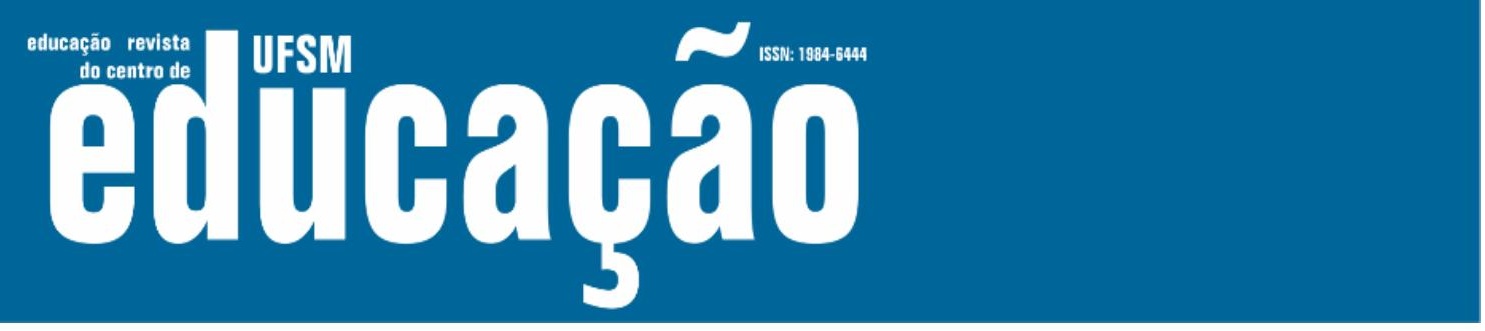

ISSN: 1984-6444 | http://dx.doi.org/10.5902/1984644435041

\title{
Modos de habitar a escola: o que somos capazes de inventar?
}

Ways of inhabiting the school: what are we capable of inventing?

\section{Deborah Vier Fischer}

Doutora em Educação, Universidade Federal do Rio Grande do Sul, Porto Alegre, Rio Grande do Sul, Brasil.

deborahvfischer@gmail.com - http://orcid.org/0000-0003-0972-2504

Luciana Gruppelli Loponte

Professora na Universidade Federal do Rio Grande do Sul, Porto Alegre, Rio Grande do Sul, Brasil. luciana.arte@gmail.com - http://orcid.org/0000-0002-0552-0529

Recebido em 04 de outubro de 2018

Aprovado em 10 de maio de 2019

Publicado em 29 de março de 2020

\section{RESUMO}

Pensar a escola de outros modos é um dos objetivos deste artigo, que busca um modo de reafirmar a vida que pulsa na escola, especialmente diante do cenário atual de desgaste da educação. Através do texto, convida-se a pensar sobre o que se passa na escola como o espaço do instituído e o que o atravessa, impossível de ser previsto e controlado. Para tal tarefa, aposta-se nos encontros entre arte e educação, convidando a olhar para a escola pelo que é possível inventar e criar. No presente artigo, busca-se trazer à visibilidade a potência do mínimo através de cenas-imagens de escola e da parceria de produções de artistas visuais contemporâneos, como Hicham Benohoud e Luis Camnitzer. Cada um a seu modo, toma a educação como matéria-prima, colaborando para pensar as relações que envolvem arte e educação. Com esses artistas e com as cenas-imagens de escola, busca-se trazer a ideia de encontros em que a escola possa olhar para a arte como caminho para pensar as minoridades que nela convivem. Como autores de referência, destacam-se Foucault, Deleuze, Sílvio Gallo e Simon Rodríguez. A partir deste artigo, acompanhado do olhar lançado a cenas-imagens de escolas, das produções de artistas visuais e filósofos que ajudam a pensá-las, espera-se que mais pessoas se sintam tocadas ou convocadas a ouvir e sentir as coisas mínimas que, sem descanso, acontecem e podem ser percebidas por quem vive a escola por dentro. Afinal, que modos de habitar a escola somos capazes de inventar?

Palavras-chave: Escola; Imagem; Arte contemporânea.

\section{ABSTRACT}

Thinking the school environment in different ways is one of the objectives of this article, which seeks a way to reaffirm the life that pulses in school, especially when faced with 


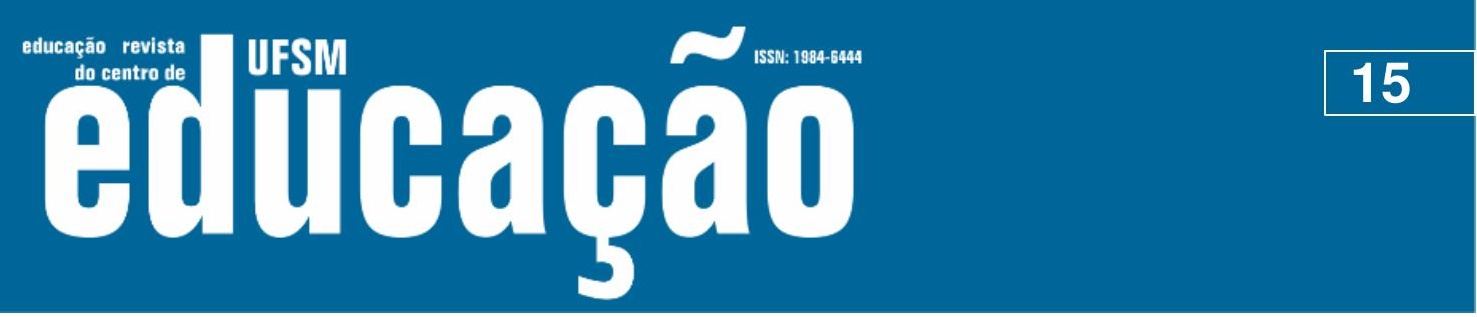

ISSN: 1984-6444 | http://dx.doi.org/10.5902/1984644435041

the current deterioration of education. The text offers an invitation to think about what goes on in the school as a space for the established and what runs through it, unpredictable and uncontrollable. This task relies on convergences between art and education, inviting readers to see the school according to what is possible to invent and create. This article seeks to bring to the fore the power of the minimum through school scenes-images and collaborations with contemporary visual artists, such as Hicham Benohoud and Luis Camnitzer. In their own different ways, both take education as a raw material, collaborating to think the relationships that involve art and education. With these artists and with the school scenes-images, the purpose is to bring up the idea of encounters in which the school can regard art as a pathway to reflect on the minorities that coexist in it. The main authors referenced in this text are Foucault, Deleuze, Sílvio Gallo and Simon Rodríguez. Accompanied by a look at the school scenes-images and by the works of visual artists and philosophers who help think the school, this article should make more people feel touched or urged to listen and feel the minimum things that restlessly take place and can be perceived by those who experience the school from the inside. After all, what ways of inhabiting the school are we capable of inventing?

Keywords: School; Image; Contemporary art.

Figura 1 - Cena-imagem 1 - A escola sorri? (em uma escola qualquer)

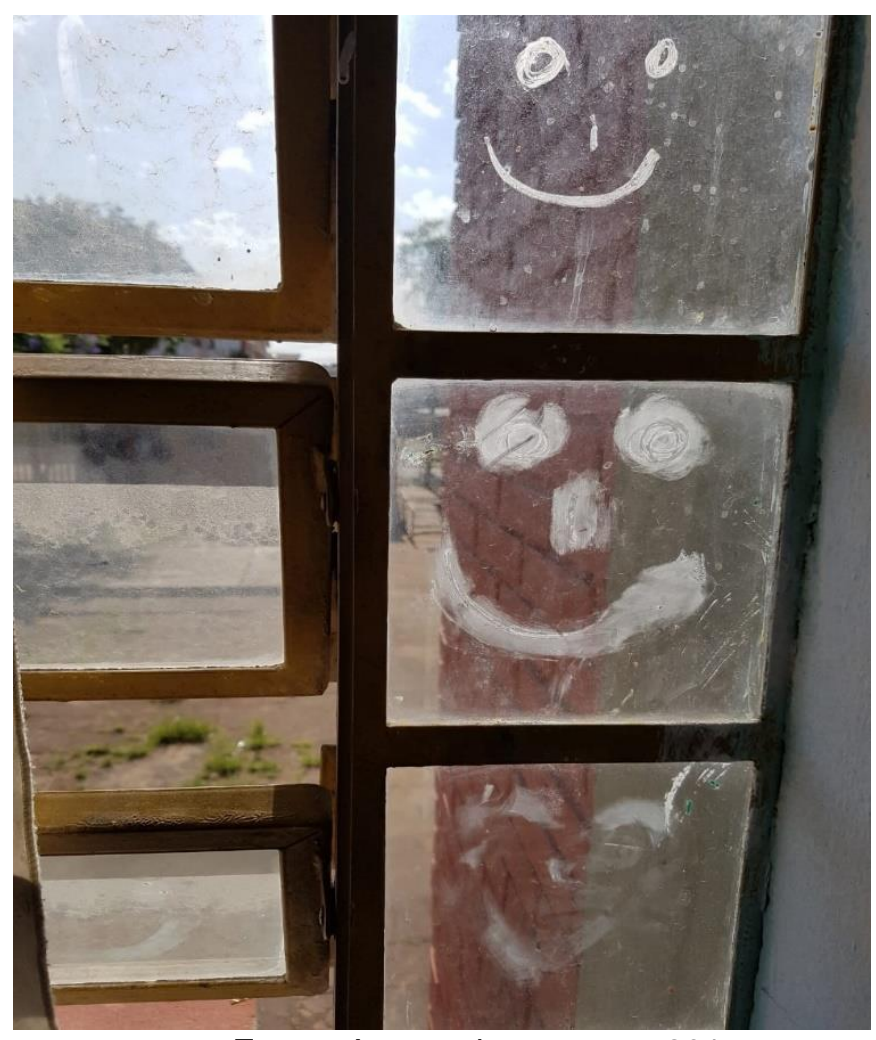

Fonte: Acervo das autoras, 2017. 


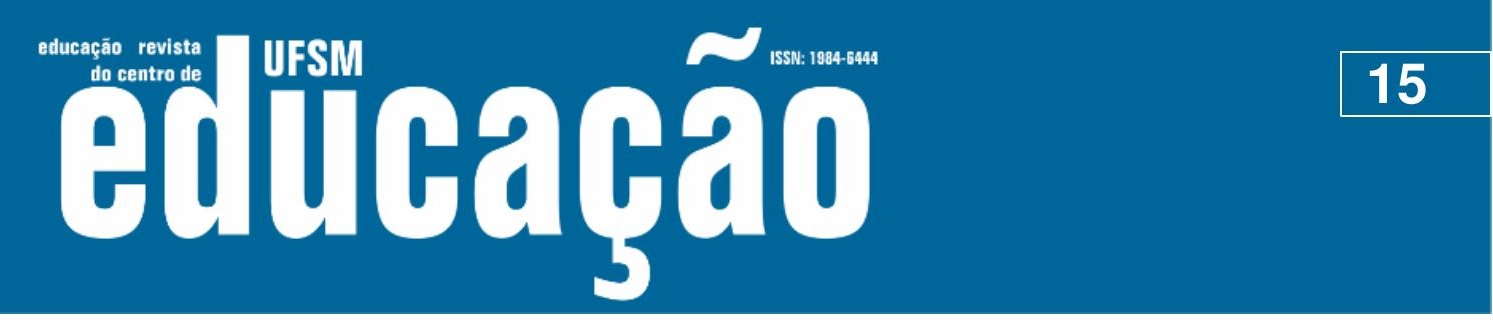

ISSN: 1984-6444 | http://dx.doi.org/10.5902/1984644435041

A história de Thomas provocou em Rodríguez um movimento de estranhamento aos modos como ele via e vivia a escola da época, fazendo com que não conseguisse mais retornar a ela do mesmo modo. Mais do que buscar interpretações ou explicações para esse ocorrido, Simón tratou de pensar em outros caminhos para olhar o que acontece na escola, com atenção aos detalhes, para aquilo que muitas vezes passa desapercebido, exercendo uma atitude que permite enxergar o que nos escapa, ao modo de Georges Perec (2016), na sua tentativa de esgotar um lugar:

Inutilizá-lo, revelar seu verdadeiro estado. Colocá-lo cru e totalmente disponível à leitura, sem máscaras, empecilhos, representações espetaculares, imagens pré-estabelecidas. Enxergá-lo na sua essência, vulgaridade, realidade, possibilidade (SILVA, 2016, p. 9).

Em companhia de Simón Rodríguez e de artistas visuais que nos desafiam a olhar a escola de outros lugares, buscamos algumas cenas-imagens que convidam a sair do lugar das familiaridades, convocam a pensar sobre o que não havia sido pensado e a estranhar práticas, buscando caminhos de pensamento para o que se vive para além do cotidiano da escola.

\section{Cenas-imagens de escola e proposições artísticas: movimentos de pensamento}

Façamos o seguinte exercício: adentrar em um espaço escolar, uma sala de aula, e usar os sentidos para perceber o que ali se passa. São diversos olhares, ruídos, gestos, movimentos. O que fazemos com isso? O que vemos? O que ouvimos? O que sentimos? De que modos essa percepção pode modificar nossas concepções sobre o que é uma escola ou o que pode uma escola? Que aulas podem ser vividas a partir do que se ouve e se percebe por dentro da escola, entendendo com Loponte (2017, p. 446), que "habitar uma escola é conviver com inúmeras e intermináveis tramas narrativas"?

Trazemos algumas cenas-imagens à conversa ${ }^{9}$, não com o intuito de interpretálas ou delas extrair algum tipo de "mensagem" ou moral, mas de pensar a escola, com elas e a partir delas, buscando, quem sabe, respostas sempre provisórias às perguntas que nos instigam: 


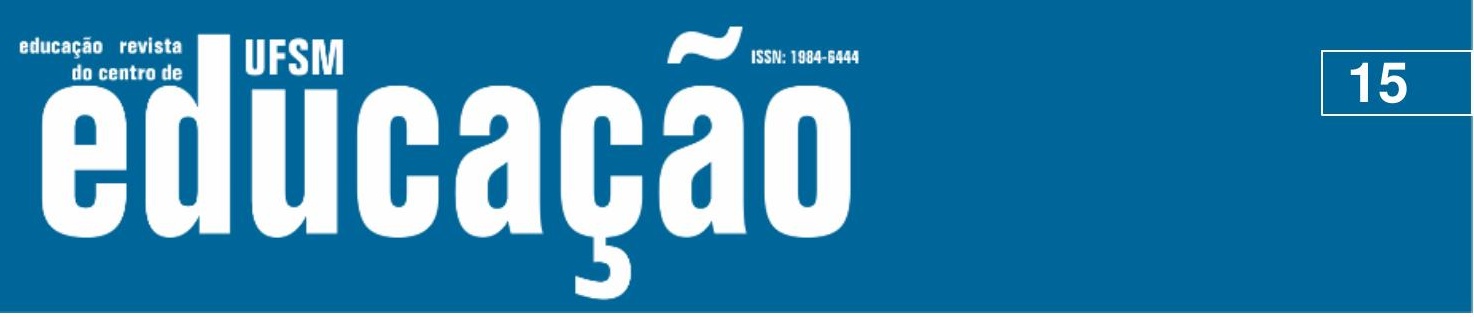

ISSN: 1984-6444 | http://dx.doi.org/10.5902/1984644435041

Meninos e meninas brincam em uma sala de aula. As crianças têm em torno de 8-9 anos de idade. Uma menina, no entanto, encontra-se sozinha em um canto da sala. Parece pensativa. Tem o olhar parado, distante. Uma colega se aproxima e a convida para brincar. Ela responde: não posso, estou com a cabeça muito cheia. Preciso encontrar um jeito de esvaziar meus pensamentos. Ficar parada e quieta acho que pode ajudar. A colega pergunta: mas o que tem no teu pensamento? Dá para me contar? E a menina responde: muitas coisas, mas elas quase não têm nome. Não são coisas muito boas. E a colega diz: vem comigo, quem sabe a gente brinca de colocar nomes nos pensamentos? E foram. (Cena-imagem de escola 2).

Figura 2 - Cena-imagem de escola 3 - Fragmentos de um momento-aula.

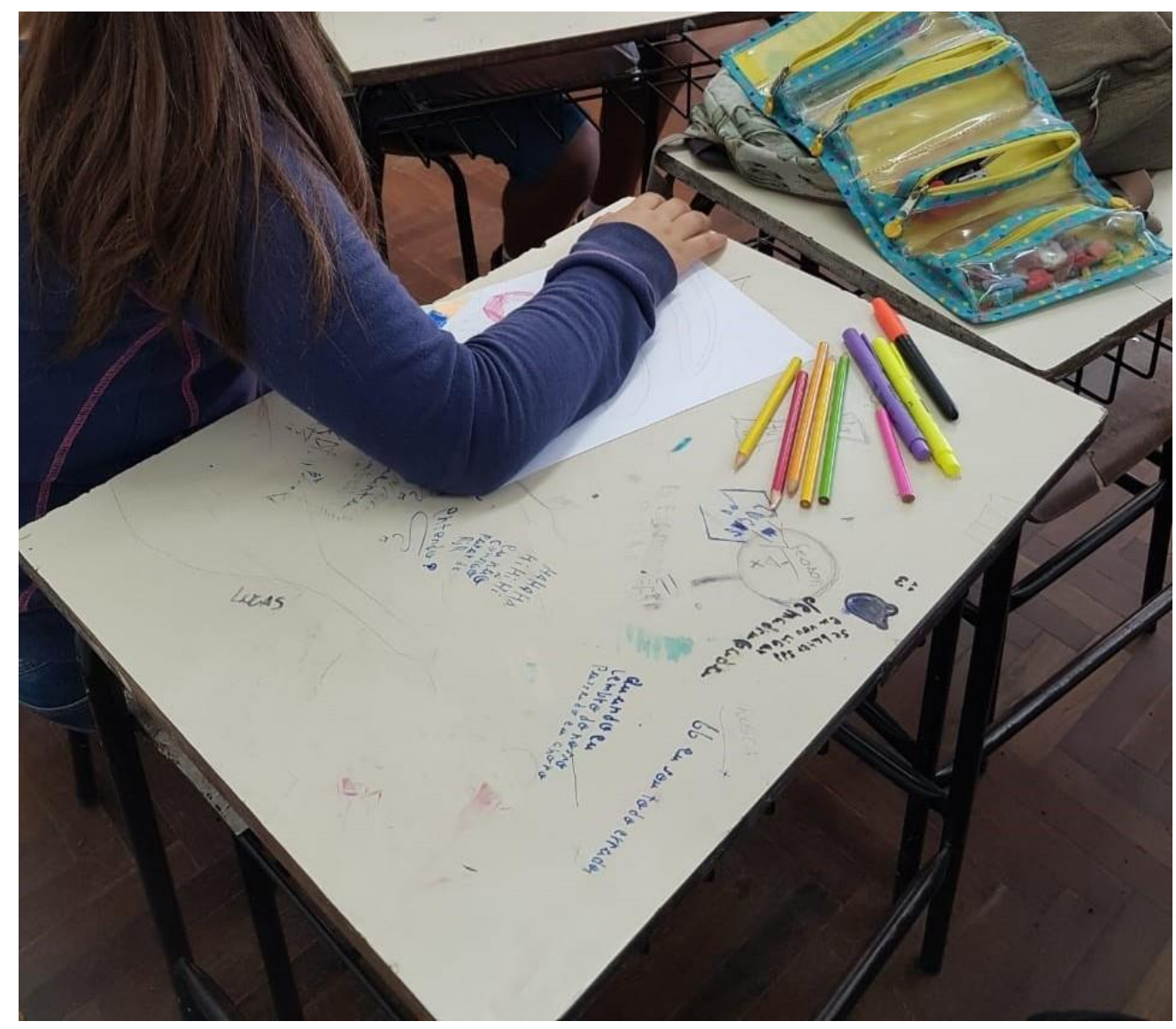

Fonte: Acervo das autoras, 2017.

A professora chega com seu caderno para a reunião com a coordenadora pedagógica. Abre-o sobre a mesa e mostra o planejamento da semana com muitas partes anuladas, com flechas, observações, interrogações, registros. Diz para a coordenadora: tenho mais de 20 anos de trabalho em sala de aula. O que vivo hoje com minha turma não cabe neste planejamento. Me dei conta que meus alunos e alunas precisam de outras coisas, de mais tempo, de mais espaço para trazerem suas questões. Meu pensamento não para, preciso de ajuda para pensar de outros jeitos. Preciso abrir outros caminhos para pensar. Cena-imagem de escola 4. 


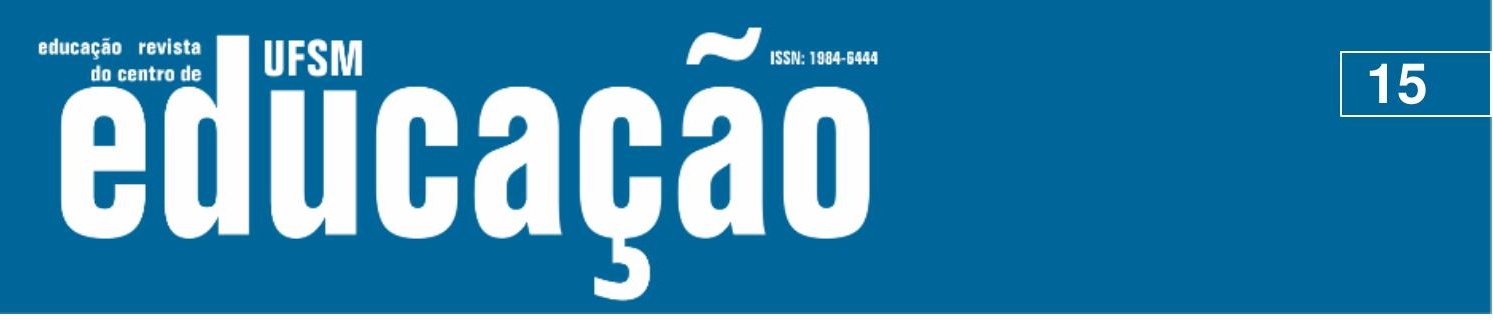

ISSN: 1984-6444 | http://dx.doi.org/10.5902/1984644435041

ideia de que "a arte é educação e a educação é arte. Uma palavra somente adquire sentido uma vez que está dentro da outra":

O artista convida uma turma de crianças de 10-11 anos para a abertura de
sua exposição em um espaço tradicional de arte da cidade. O chão da sala
de exposição está repleto de folhas secas do outono, objeto de interesse e
pesquisa do artista. Ao fundo da sala, projetado na parede, um filme do
processo de coleta das folhas e da preparação do "tapete" para a exposição.
As crianças entram na sala e já nas primeiras pisadas, ao ouvirem os estalos
das follas secas, são tomadas de alegria e curiosidade. Poderiam pisar ali?
Poderiam tocar nas folhas? Chutá-las para longe? Poderiam jogar seu corpo
sobre aquele tapete? O que o artista esperava que elas fizessem ali naquele
espaço? O artista, presente, nada dizia, apenas olhava, acompanhava cada
gesto atentamente. As crianças rapidamente entenderam o recado: aquele
espaço poderia ser explorado, modificado. O material ali exposto passara a
ser objeto de interação delas e do seu corpo. O movimento de dezoito corpos
infantis espalhou as folhas, modificou o cenário, outra obra se compôs. O
artista? Observando. Uma nuvem de poeira tomou conta do espaço, a sala
ficou encoberta. Nada disso havia sido previsto, no entanto, aconteceu. Do
lado fora, afoitos, seguranças do museu, tentavam, sem sucesso, entrar na
sala e acalmar aqueles corpos suados, cansados, felizes. O artista, por sua
vez, mostrava a eles que estava tudo certo, que as crianças estavam
trabalhando a partir de sua obra, elas estavam criando. Cena-imagem de
escola 5 .

Exercitar esse olhar para a arte, a considerando como uma "plataforma para pensar"13, nos faz acreditar na possibilidade de outros encontros entre arte e educação, que podem transformar o espaço de uma sala de aula ou mesmo de um museu, ou ainda trazer à tona cenas-imagens de escola, evidenciando aquilo que até então não havia sido considerado.

Assim, tanto nas cenas-imagens trazidas à discussão, quanto nas obras escolhidas para abrir essa conversa, podemos localizar alguns movimentos de liberação da "moral do escolarismo", termo usado por Francisco Jódar e Lucía Gómez (2004), em referência a Foucault, quando convida a colocar em questão o modo hermenêutico escolar de interpretar, traduzir, recolher o que foi disseminado. Os autores chamam a atenção para a necessidade de realizarmos um "exercício sobre inéditas perguntas e ensaio crítico de novas respostas que está orientado em direção à transformação daquilo que somos e à participação na atualidade do mundo que nos rodeia e limita" (JÓDAR; GÓMEZ, 2004, p. 140). Esse poderia ser um caminho, quem sabe, para provocar um movimento que se afaste da moral afinada que na escola parece se perpetuar, através de uma certa sensatez que faz com que só se interrogue 


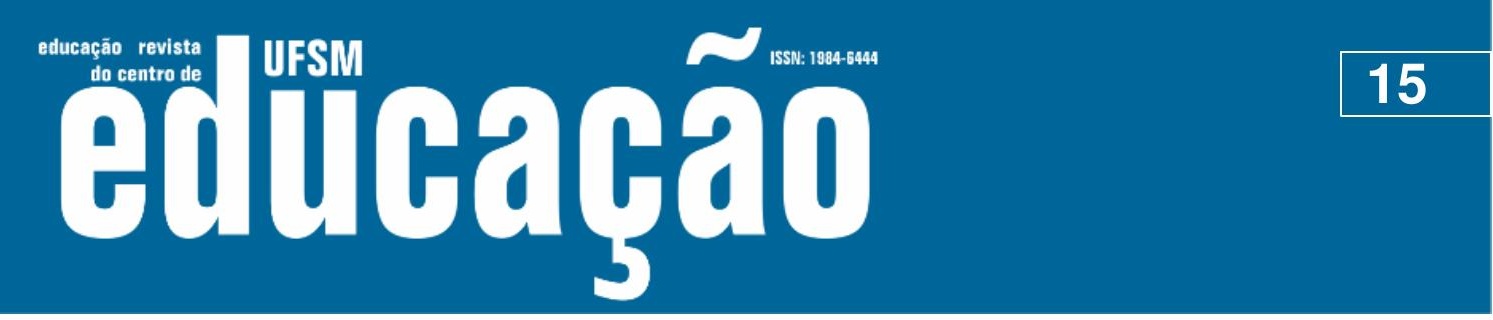

ISSN: 1984-6444 | http://dx.doi.org/10.5902/1984644435041

pensar, não permitindo que habitemos a escola do mesmo modo. Tal como Ribetto (2014, p. 83), temos a ambição de escrever (ou pensar, imaginar, inventar) "em minúsculas, alterando a própria gramática do campo para, talvez, possibilitar algumas perguntas sobre sua própria sintaxe". Não desconhecemos o cenário difícil para a educação que nos assola e nem temos a intenção de menosprezar as macropolíticas que têm configurado nosso trabalho ou edulcorar a tarefa de habitar a escola. Ainda assim, ali estamos, ali insistimos, ali inventamos.

\section{Referências}

ALLEN, Felicity (ed.). Education. London: Whitechapel Gallery, 2011.

ALZUGARAY, Paula. Luis Camnitzer: arte como forma de pensar. Revista Select, 33, jan. 2017. Disponível em: https://www.select.art.br/luis-camnitzer-arte-como-formade-pensar/. Acesso em 03 de agosto de 2018.

BISHOP, Claire. Artificial Hells: Participatory Art and the Politics of Spectatorship. Brooklyn, Nueva York, EUA: Verso, 2012.

CAMNITZER, Luís. Arte y pedagogia. Esfera Pública, 2015. Disponível em: http://esferapublica.org/nfblog/arte-y-pedagogia/ Acesso em 16 de abril de 2016.

CAMNITZER, Luís. Ni arte ni educación. In: GRUPO DE EDUCACIÓN DE MATADERO MADRID. Ni arte ni educación: Una experiencia en la que lo pedagógico vertebra lo artístico. Madrid: catarata, 2017. p. 19-25.

CANCLINI, Néstor Garcia. A sociedade sem relato: antropologia e estética da iminência. São Paulo: EDUSP, 2012.

FISCHER, Deborah Vier. Pensar com cenas de escola: a arte, o estranho, o mínimo. Porto Alegre, RS, UFRGS, 2019. Tese (Doutorado em Educação). Programa de Pós-Graduação em Educação, Faculdade de Educação, UFRGS, 2019. Disponível em: https://lume.ufrgs.br/handle/10183/197436. Acesso em 6 ago. 2019.

FOUCAULT, Michel. História da sexualidade 2: o uso dos prazeres. São Paulo: Paz e Terra, 2014.

GALLO, Sílvio. Deleuze \& a Educação. Belo Horizonte: Autêntica Editora, 2003.

GALLO, Sílvio. mínimo múltiplo comum. In: RIBETTO, Anelice (org.). políticas, poéticas e práticas pedagógicas (com minúsculas). Rio de Janeiro: Lamparina, FAPERJ, 2014, p. 20-33. 


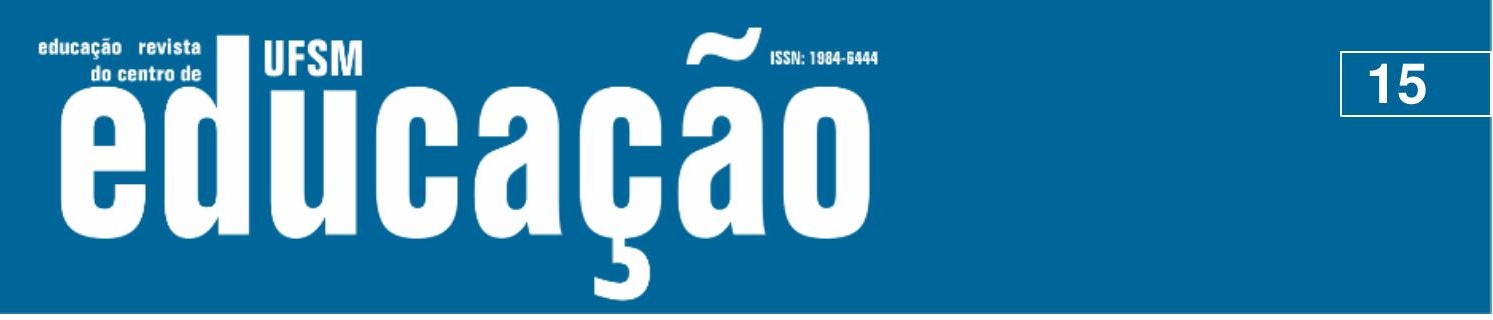

ISSN: 1984-6444 | http://dx.doi.org/10.5902/1984644435041

GALLO, Sílvio. Pensar a escola com Foucault: além da sombra da vigilância. In: CARVALHO, Alexandre Filordi de. (org.). Repensar a educação: 40 anos após Vigiar e Punir. São Paulo: Editora Livraria da Física, 2015, p. 427-449.

DELEUZE, Gilles; GUATTARI, Félix. Kafka: por uma literatura menor. Rio de Janeiro: Imago, 1977.

GONÇALVES, Mônica Hoff. A virada educacional nas práticas artísticas e curatoriais contemporâneas e 0 contexto de arte brasileiro. Dissertação (Mestrado em Artes Visuais), UFRGS, 2014.

JÓDAR, Francisco; GÓMEZ, Lucía. Experimentar o presente: sobre a conformação de novas identidades. Educação \& Realidade, 29 (1), 139-153, jan-jun 2004. Disponível em: http://www.seer.ufrgs.br/index.php/educacaoerealidade/article/view/25422/14748.Ac esso em 03 de agosto de 2018.

KOHAN, Walter Omar. O mestre inventor: Relatos de um viajante educador. Belo Horizonte: Autêntica, 2013.

LARROSA, Jorge (org.). Elogio da escola. Belo Horizonte: Autêntica, 2017.

LEYTON, Daina. Curar uma exposição sobre a escola: um exercício de pensamento. In: LARROSA, Jorge (org.). Elogio da escola. Belo Horizonte: Autêntica, 2017, p. 235-248.

LOPONTE, Luciana Gruppelli. Tudo isso que chamamos de formação estética: ressonâncias para a docência. Revista Brasileira de Educação. São Paulo, v. 22, 2017, p. 429-452.

MASSCHELEIN, Jan, SIMONS, Maarten. Em defesa da escola: uma questão pública. Belo Horizonte: Autêntica, 2014.

MORSCH, Carmen. Lo común disensual: producción de saberes críticos en exposiciones. ERRATA\#, Bogotá, Colômbia, no. 16, jul-dic 2016.

MOSSI, Cristian Poletti. Um corpo-sem-órgãos, sobrejustaposições: quem a pesquisa [em educação] pensa que é. Santa Maria: UFSM, 2017.

PEREC, Georges. Tentativa de esgotamento de um local parisiense. São Paulo: Gustavo Gili, 2016.

PERONI, Vera Maria Vidal, CAETANO, Maria Raquel, LIMA, Paula Valim de. Reformas educacionais de hoje: as implicações para a democracia. Retratos da escola, v. 11, p. 415-432, 2018. Disponível em: http://retratosdaescola.emnuvens.com.br/rde/article/view/793. Acesso em 03 de agosto de 2018. 


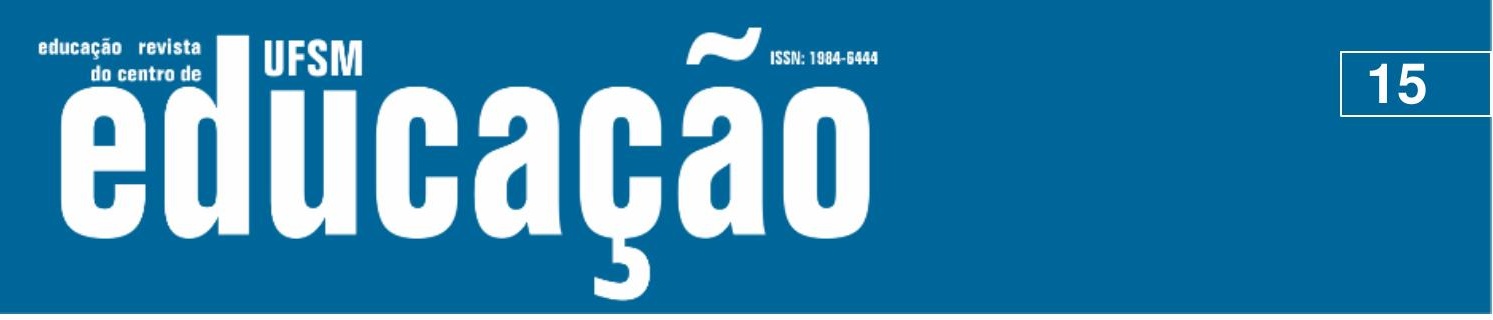

ISSN: 1984-6444 | http://dx.doi.org/10.5902/1984644435041

PERONI, Vera Maria Vidal. Múltiplas formas de materialização do privado na educação básica pública no Brasil: sujeitos e conteúdo da proposta. Currículo sem fronteiras, $\quad$ v. 18, p. 1-27, 2018. Disponível em: http://www.curriculosemfronteiras.org/vol18iss1articles/peroni.pdf Acesso em 03 de agosto de 2018.

PODESVA, Kristina Lee. A Pedagogical Turn: Brief Notes on Education as Art. Filip, 6, Vancouver, Canadá, Summer 2007. Disponível em: https://fillip.ca/content/apedagogical-turn. Acesso em 06 de agosto de 2018.

ROGOFF, Irit. El giro. Arte y políticas de identidad, vol. 4, jun 2011, p. 253-266. Disponível em: http://revistas.um.es/api/article/viewFile/146111/130521. Acesso em 06 de agosto de 2018.

RIBETTO, Anelice. dos saberes risíveis aos saberes menores na educação. In: RIBETTO, Anelice (org.). políticas, poéticas e práticas pedagógicas (com minúsculas). Rio de Janeiro: Lamparina, FAPERJ, 2014. p. 83-98.

SÁENZ OBREGÓN, Javier. La escuela como dispositivo estético. In: FRIGERIO, Graciela; DIKER, Gabriela (org.). Educar: (sobre) impresiones estéticas. Buenos Aires: Del Estante Editorial, 2007, p. 73-86.

SAYÃO, Roseli, AQUINO, Julio Groppa. Em defesa da escola. Campinas, SP: Papirus, 2004.

SILVA, Ricardo Luís. Prefácio - Experiência do inútil, enfim. In: PEREC, Georges. Tentativa de esgotamento de um local parisiense. São Paulo: Gustavo Gili, 2016.

SIMONS, Maarten; MASSCHELEIN, Jan. Experiências escolares: uma tentativa de encontrar uma voz pedagógica. In: LARROSA, Jorge (org.). Elogio da escola. Belo Horizonte: Autêntica, 2017, p. 41-63.

VARELA, Julia; ALVAREZ-URIA, Fernando. A maquinaria escolar, Teoria \& Educação, 6, p. 68-96, 1992.

VEIGA-NETO, Alfredo; LOPES, Maura Corcini. Para pensar de outros modos a modernidade pedagógica. ETD - Educação Temática Digital, Campinas, São Paulo, v. 12, no 1, p. 147-166, 2010. Disponível em: https://periodicos.sbu.unicamp.br/ojs/index.php/etd/article/view/25422/14748. Acesso em 03 de agosto de 2018.

\section{Correspondência}

Deborah Vier Fischer - Universidade Federal do Rio Grande do Sul - Av. Paulo Gama, 110. Farroupilha, CEP 90040-060, Porto Alegre, Rio Grande do Sul, Brasil. 


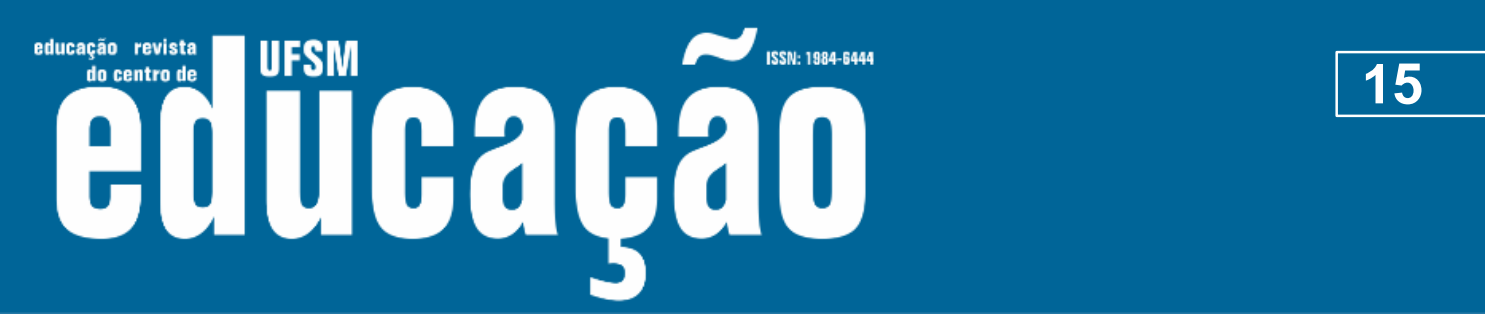

ISSN: 1984-6444 | http://dx.doi.org/10.5902/1984644435041

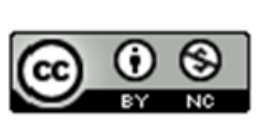

\section{This work is licensed under a Creative Commons Attribution-NonCommercial 4.0 International (CC BY-NC 4.0)}

\section{Notas}

\footnotetext{
${ }^{1}$ Menor aqui compreendido por Deleuze e Guattari (1977), conforme exploraremos mais adiante.

${ }^{2} \mathrm{O}$ seminário foi intitulado de Modos de pensar e habitar a escola: urgências, pesquisa e arte, oferecido pelo Programa de Pós-Graduação em Educação da Universidade Federal do Rio Grande do Sul, em 2017, sob a coordenação da professora Luciana Gruppelli Loponte.

${ }^{3}$ Tese de autoria de Deborah Vier Fischer, defendida em 2019, que tem como título: Pensar com cenas de escola: a arte, o estranho, o mínimo.

${ }^{4}$ O ARTEVERSA - Grupo de estudo e pesquisa em arte e docência, foi criado em 2015 na Faculdade de Educação da UFRGS (www.ufrgs.br/arteversa).
}

${ }^{5}$ A opção por não referir uma determinada escola ou conjunto de escolas, tem como referencial teórico os autores Deleuze e Guattari (1977) quando propõem pensar a partir do artigo indefinido "um/uma", pensando não mais em um sujeito de enunciação, mas à ideia de um agenciamento coletivo (DELEUZE; GUATTARI, 1997, p. 53). Referir não determinada escola, mas "uma" escola, destitui a ideia de uma pessoalidade, de uma generalidade identitária, liberando o pensamento para pensar "naquilo que ele tem de não formado" (DELEUZE; GUATTARI, 1997, p. 53),

${ }^{6}$ A obra de Simón Rodríguez, ainda desconhecida por muitos, tem sido apresentada no Brasil por Walter Kohan , nos inspirando a "pensar com Simón Rodríguez uma forma de reunir a filosofia, a educação e a vida" (KOHAN, 2013, p. 19).

${ }^{7}$ A BNCC é um documento de caráter normativo que tem como objetivo definir o conjunto de "aprendizagens essenciais que todos os alunos devem desenvolver ao longo das etapas e modalidades da Educação Básica, de modo a que tenham assegurados seus direitos de aprendizagem e desenvolvimento, em conformidade com o que preceitua o Plano Nacional de Educação" (http://basenacionalcomum.mec.gov.br).

8 “A história de Thomas" está publicada detalhadamente no livro de Kohan (2013, p. 30-32).

9 As cenas-imagens 2 e 4 foram coletadas em situações escolares, registradas em cadernos de escola da pesquisadora Deborah Vier Fischer. Fazem parte da coleção de cenas que compõe o material de análise da sua tese de doutorado. Não são identificadas, mantendo-se a ideia de uma escola, qualquer escola, defendida pela autora.

${ }^{10}$ Deleuze \& Guattari, ao discutirem sobre a produção literária de Kafka, um judeu de Praga impossibilitado de escrever de outra maneira que não em alemão, trazem a ideia de uma literatura menor, como sendo não a de uma "língua menor, mas antes o que uma minoria faz em uma língua maior" (DELEUZE; GUATTARI, 1977, p. 25). Uma língua desterritorializada própria a usos menores, estranhos, de acordo com os autores.

${ }^{11}$ La salle de classe - Hicham Benohoud. Disponível em: http://hichambenohoud.com/benohoud/.

${ }^{12}$ A imagem da obra referida está disponível neste site: https://www.select.art.br/luis-camnitzer-arte-como-formade-pensar/.

${ }^{13} \mathrm{O}$ termo é apropriado a partir de discussão empreendida por Canclini (2012), a partir de obras do artista Gabriel Orozco. 